\title{
STUDI PERUBAHAN DASAR SUNGAI AKIBAT KENAIKAN MUKA AIR DI HILIR SUNGAI JENELATA KAB. GOWA
}

\author{
Farida Gaffar ${ }^{1}$, Indriyanti ${ }^{2}$, Fauziah Latif ${ }^{3}$ \\ ${ }^{1}$ Program Studi Teknik Pengairan, Universitas Muhammadiyah Makassar \\ Email : gaffarfarida970@yahoo.com \\ ${ }^{2}$ Program Studi Teknik Pengairan, Universitas Muhammadiyah Makassar \\ Email: indriyanti.azis@gmail.com \\ ${ }^{3}$ Program Studi Teknik Pengairan, Universitas Muhammadiyah Makassar \\ Email: Fauziahlatif574@gmail.com
}

\begin{abstract}
ABSTRAK
Sungai Jenelata yang memiliki peran penting dalam pengendalian banjir Kota Makassar dan Kabupaten Gowa memerlukan perhatian khusus terutama setelah terjadinya longsor di hulu sungai ini yaitu di Gunung Sorong yang memiliki volume longsor 235 juta $\mathrm{m}^{3}$ lumpur dan pasir yang terjadi pada tanggal 26 Maret 2004. Pasir dan lumpur yang terdapat pada bagian hulu sungai akan terbawa di sepanjang sungai yang dapat mempengaruhi karakteristik aliran dan perubahan dasar sungai di sepanjang sungai Jenelata. Daerah bagian hilir sungai Jenelata yang mengalami perubahan karakterstik aliran akan berdampak pada perubahan dasar sungai yang dimana material - material sungai seperti halnya lumpur, pasir, batuan maupun kotoran yang tidak mampu lagi dibawah oleh aliran sungai yang dimana dulunya aliran sungai tersebut cepat menjadi sangat lambat sehingga mendorong terjadinya pengendapan sedimen yang dimana dapat merubah permukanan dasar sungai. Tujuan dari penelitian ini adalah untuk mengetahui karakteristik aliran di sungai Jeneleta dan mengetahui pengaruh perubahan dasar sungai terhadap karakteristik aliran pada bagian hilir sungai Jenalata.Hasil penelitian menunjukkan karakteristik aliran berupa angka Froude menunjukkan pada bagian hilir sungai Jenelata, pada kondisi muka air minimum $\mathrm{Fr}$ : 0.067, muka air normal $\mathrm{Fr}$ : 0.069 dan muka air maksimum $\mathrm{Fr}$ : 0.073 dan Berdasarkan konfigurasi dasar sungai bahwa pada bagian hilir sungai Jenelata berbentuk Anti Dunnes dengan dasar bentuk gelombang yang tidak simetris dimana nilai $k>0,01$ meter
\end{abstract}

Kata kunci : perubahan dasar, karakteristi aliran, Tinggi Muka Air (h)

\begin{abstract}
The Jenelata River which has an important role in flood control in Makassar City and Gowa Regency requires special attention, especially after the landslide in the upper reaches of this river, namely Mount Sorong which has a landslide volume of 235 million $m 3$ of mud and sand which occurred on March 26, 2004. Sand and mud those in the upper reaches of the river will be carried along the river which can affect the flow characteristics and changes in the riverbed along the Jenelata river. The downstream area of the Jenelata river that experiences changes in flow characteristics will have an impact on changes in the river bed where river materials such as mud, sand, rock or dirt that are no longer able to be brought under by the river flow, where the river flow was fast, became very slow so that encourage sediment deposition which can change the surface of the river bed. The purpose of this study was to determine the flow characteristics of the Jeneleta river and to determine the effect of changes in the riverbed on the flow characteristics of the downstream part of the Jenalata river. The results showed that the flow characteristics in the form of Froude number showed that in the lower part of the Jenelata river, the minimum water level was Fr: 0.067, the normal water level was Fr: 0.069 and the maximum water level was Fr: 0.073 and based on the river bed configuration that the downstream part of the Jenelata river was in the form of Anti. Dunnes based on asymmetrical waveforms where $k$ value $>0.01$ meters
\end{abstract}

Keywords: configuration of base, flow characteristics, Water Level ( $h$ )

E - ISSN : 27150763

P - ISSN : 19799764 


\section{PENDAHULUAN}

Sungai mempunyai peranan sangat penting bagi kebutuhan manusia yang pada saat ini tidak dapat dipungkiri. Hal ini menyebabkan fungsi sungai bukan sekedar sarana mengalirkan air, akan tetapi mampu memberikan nilai ekonomis dalam berbagai bidang, mulai dari penyediaan air baku, pertanian, sarana transportasi, pembangkit listrik dan lain sebagainya. Sungai Jenelata merupakan salah satu anak sungai Jeneberang yang berada di Kecamatan Parangloe Kabupaten Gowa Provinsi Sulawesi Selatan. Sungai ini berada di wilayah Desa Moncongloe Kecamatan Manuju. Secara goegrafis terletak $5^{\circ}$ $17^{\prime} 24,02^{\prime \prime}$ LS dan $119^{\circ} 36^{\prime}-119^{\circ} 34^{\prime} 46,75^{\prime \prime}$ BT, dengan panjang sungai 40 kilometer.

Sungai Jenelata yang memiliki peran penting dalam pengendalian banjir Kota Makassar dan Kabupaten Gowa memerlukan perhatian khusus terutama setelah terjadinya longsor di hulu sungai ini yaitu di Gunung Sorong yang memiliki volume longsor 235 juta $\mathrm{m}^{3}$ lumpur dan pasir yang terjadi pada tanggal 26 Maret 2004. Pasir dan lumpur yang terdapat pada bagian hulu sungai akan terbawa di sepanjang sungai yang dapat mempengaruhi karakteristik aliran dan

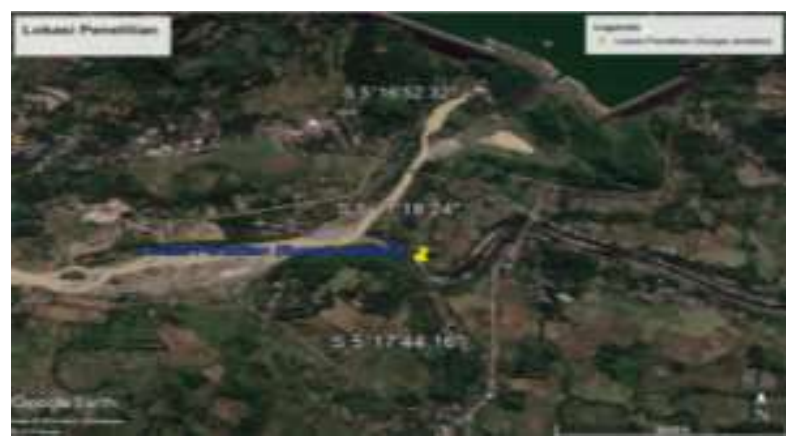

perubahan dasar sungai di sepanjang sungai Jenelata.

Daerah bagian hilir sungai Jenelata yang mengalami perubahan karakterstik aliran akan berdampak pada perubahan dasar sungai yang dimana material - material sungai seperti halnya lumpur, pasir, batuan maupun kotoran yang tidak mampu lagi dibawah oleh aliran sungai yang dimana dulunya aliran sungai tersebut cepat (Super Kritis dan Kritis) menjadi sangat lambat (Sub Kritis) sehingga mendorong terjadinya pengendapan sedimen yang dimana dapat merubah permukanan dasar sungai.

Tujuan dari penelitian ini adalah menganalisis karakteristik aliran ditinjau dari angka Froude (Fr) dan menganalisis pengaruh karakteristik aliran terhadap perubahan dasar sungai yang diakibatkan oleh kenaikan muka air di hilir sungai Jenelata.

\section{METODE PENELITIAN}

Penelitian dilakukan di bagian hilir sungai Jenelata Kec. Manuju Kab. Gowa Provinsi Sulawesi Selatan. Sungai ini berada di wilayah Desa Moncongloe Kecamatan Manuju. Secara goegrafis terletak $5^{\circ}$ 17'24,02' LS dan $119^{\circ} 36^{\prime}-119^{\circ} 34^{\prime} 46,75^{\prime \prime}$ BT, dengan panjang sungai 50 meter.

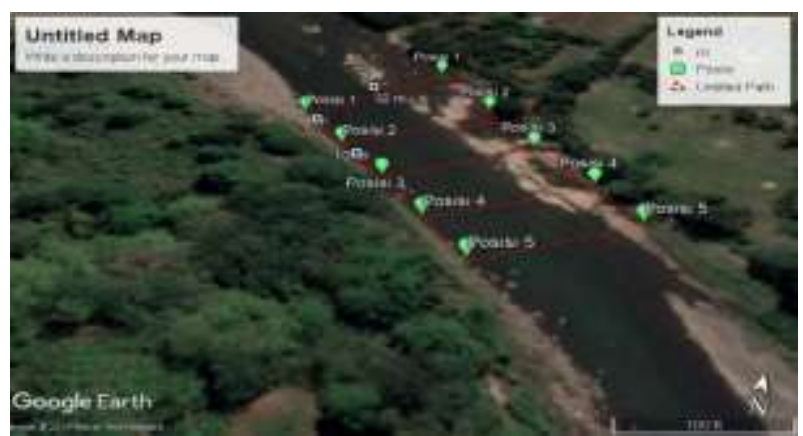

Gambar 1. Layout Sungai Jenelata dan Tampak memanjang sungai Jenelata

\section{Sumber Data}

Pada penelitian ini akan menggunkan dua sumber data, yaitu :
1. Data primer yaitu data yang diperoleh langsung oleh peneliti dari lokasi penelitian, berupa debit aliran, 
kecepatan aliran, kedalaman muka air, serta lebar saluran.

2. Data sekunder yaitu data yang diambil dari intansi yang terkait, yaitu diperoleh dari Balai Besar Wilayah Sungai (BBWS) Pompengan Jeneberang. Adapun data-data yang diperlukan meliputi debit aliran, topografi, kemiringan dasar sungai, serta peta lokasi penelitian.

\section{Prosedur Penelitian}

\section{Prosedur Penelitian}

Langkah-langkah dalam penelitian ini, sebagai berikut :

1. Memasang tali dari sisi kanan sungai ke sisi kiri sungai

2. Setelah melakukan pemasangan tali kemudian dilanjutkan dengan dengan pemasangan patok mulai dari patok P0 sampai P16

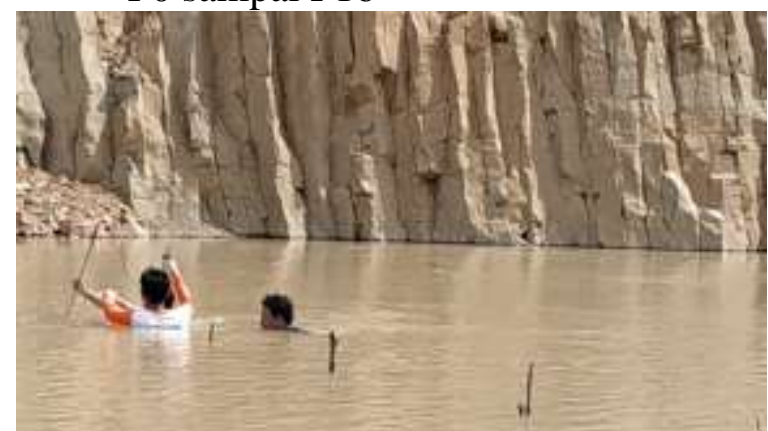

Gambar 2. Pemasangan titik patok tempat pengambilan data

3. Setelah dilakukan pemasangan patok kemudian dilakukan pengukuran kecepatan aliran aliran menggunakan alat current meter guna untuk mengetahui kecepatan aliran pada tiaptiap patok serta untuk mengetahui suhu (T) pada saluran tersebut.

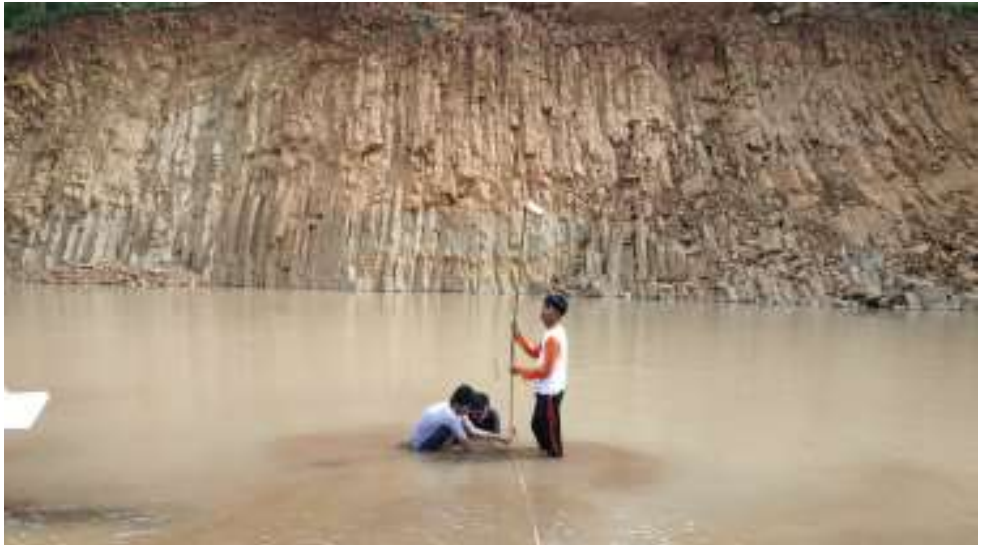

Gambar 3. Mengukur kecepatan aliran menggunakan alat Curren Meter

4. Prodesur ini dilakukan berlangung selama 5 kali pengambilan data lapangan.

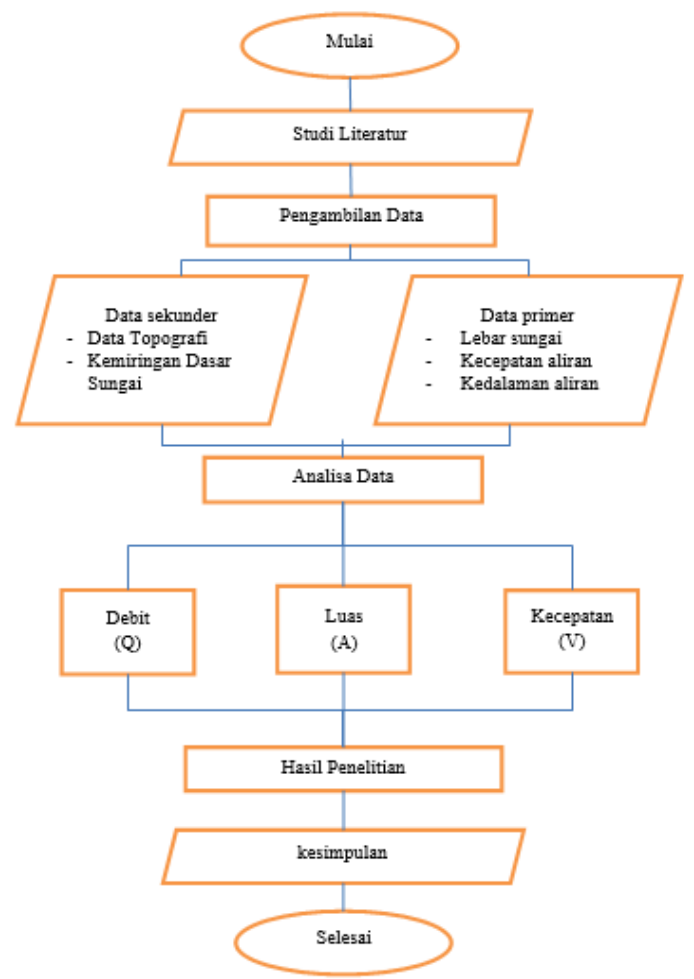

HASIL DAN PEMBAHASAN

Adapun data yang diperoleh dari hasil pengukuran data lapangan di bagian hilir sungai Jenelata dengan kondisi muka air 
minimum, normal dan maksimum dapat dilihat pada grafik hubungan antara debit dan kecepatan, hubungan antara debit dan kedalaman aliran

\section{Hubungan antara debit aliran dengan kecepatan aliran}
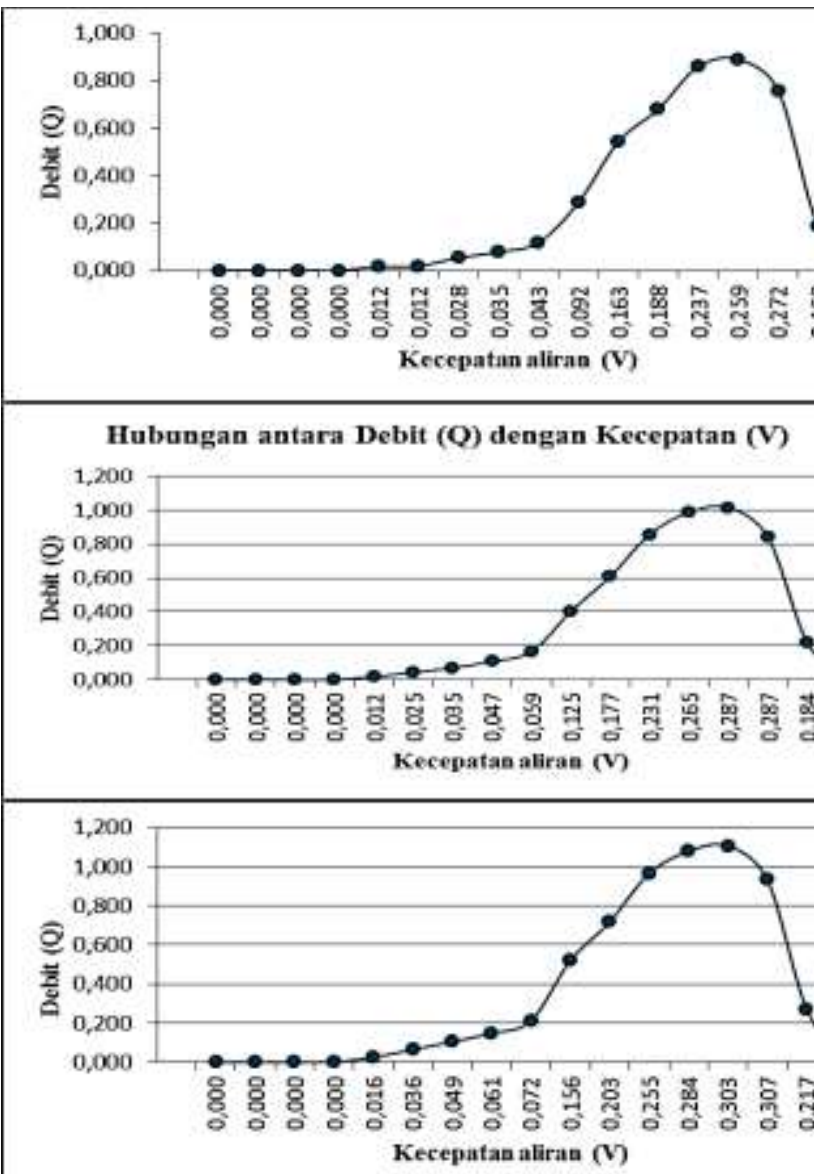

Gambar 5. Grafik Hubungan Antara Debit (Q) Dengan Kecepatan

Aliran (V) Muka Air Minimum, Normal Dan Maksimal

Berdasarkan gambar 5 hubungan antara debit dengan kecepatan aliran menunjukkan bahwa semakin besar kecepatan aliran suatu penampang sungai maka semakin besar pula debitnya.

\section{Hubungan antara debit aliran dengan kedalaman aliran}

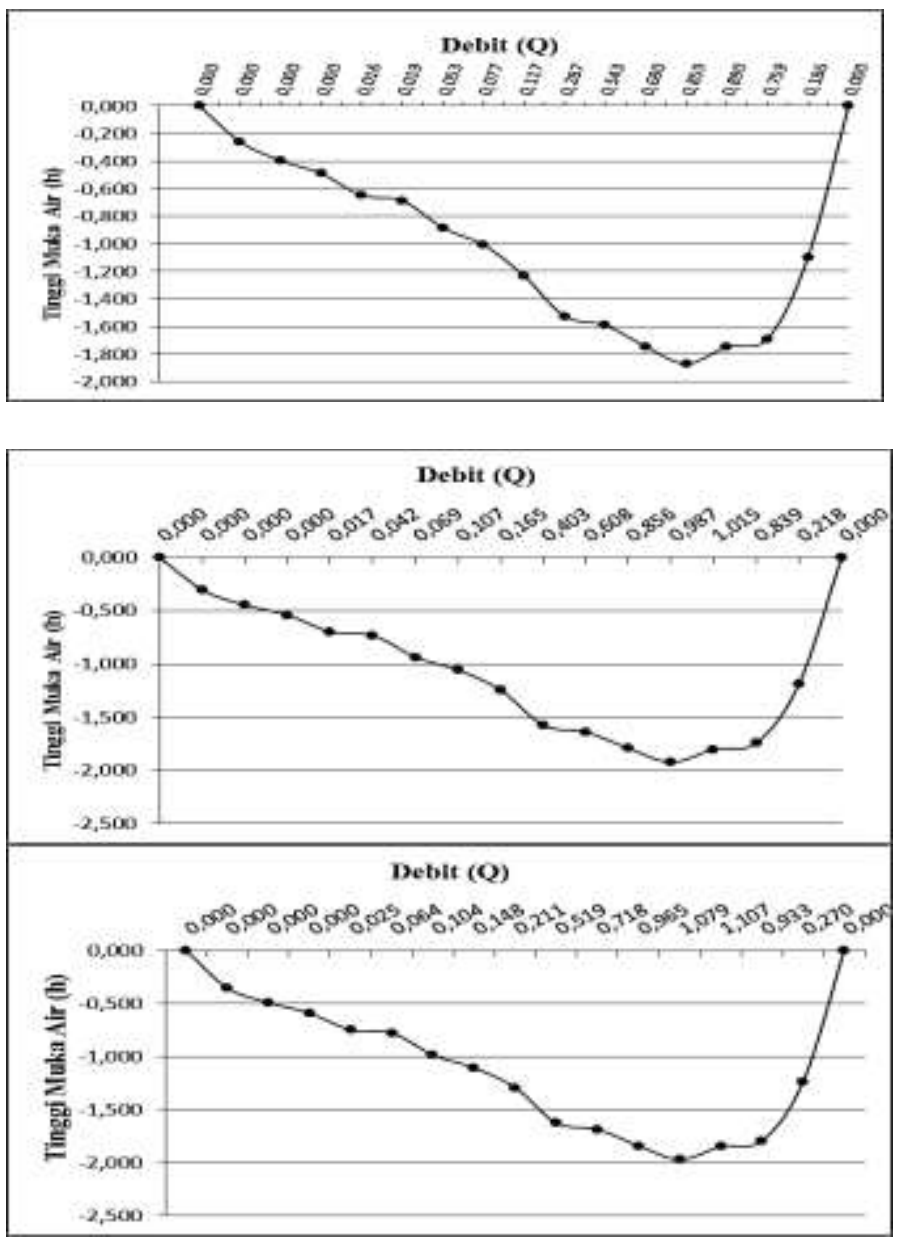

Gambar 6. Grafik Hubungan Antara Debit (Q) Dengan Kedalaman

Aliran (h) Muka Air Maksimum

Berdasarkan Gambar 6, hubungan antara debit aliran dengan kedalaman aliran menunjukkan bahwa semakin besar kedalaman aliran suatu penampang sungai maka semakin besar pula debitnya.

Perbandingan bilangan Froude (Fr) pada setiap titik pengamatan dapat dilihat pada gambar dengan kondisi muka air minimum, normal dan maksimum 


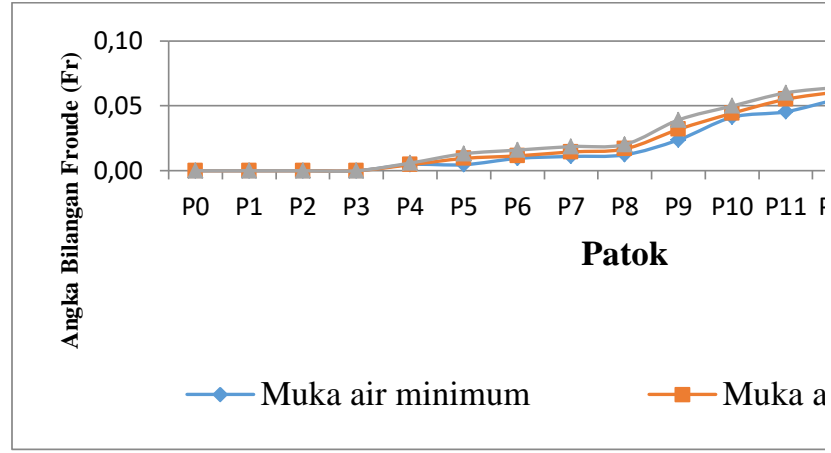

Gambar 7. Grafik Perbandingan

Bilangan Froude Pada Saat Muka Air Minimum, Normal

Dan Maksimum

Berdasarkan gambar hubungan bilangan Froude (Fr) maka Angka Froude pada muka air min yaitu 0,067, angka Froude pada muka air normal yaitu 0,069 dan angka Froude pada muka air maksimum yaitu 0,073 .

\section{Analisa Perubahan dasar sungai}

Untuk mengetahui bentuk konfigurasi dasar sungai, dalam penelitian ini dengan menggunakan grafik Albertson, yaitu membandingkan antara angka Froude $\frac{\tau_{o}}{\left(\rho_{s}-\rho_{w}\right) g d}$ dengan membandingkan antara $R e=\frac{U_{*}}{v}$ dengan $\frac{U_{*}}{w}$. Hasil pengamatan konfigurasi dasar sungai dapat dilihat gambar berikut :

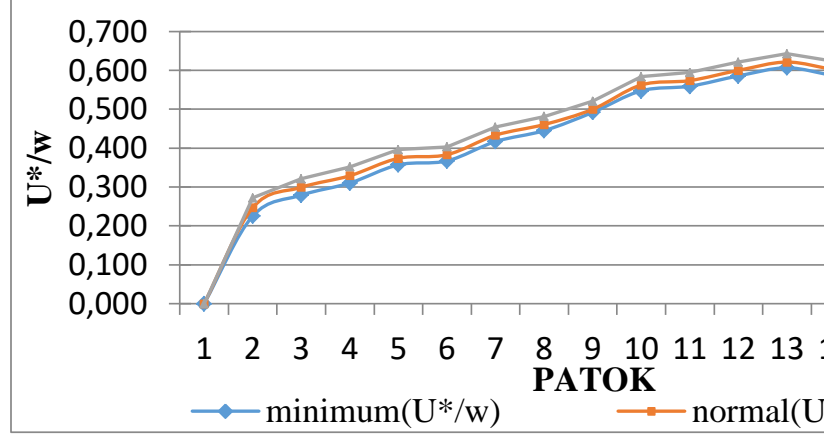

Gambar 8. Perbandingan konfigurasi sungai pada Saat Fluktuasi

Minimum dan Fluktuasi Normal
Berdasarkan gambar 8 Perbandingan konfigurasi sungai pada saat fluktuasi minimum, normal dan maksimum maka perubahan konfigurasi dasar pada bagian hilir sungai Jenelata bentuk konfigurasi dasar sungainya yaitu anti dune (grafik Albertson : 1958).

\section{KESIMPULAN}

Berdasarkan karakteristik aliran berupa angka Froude menunjukkan pada bagian hilir sungai Jenelata, pada kondisi muka air minimum $\mathrm{Fr}$ : 0.067, muka air normal Fr : 0.069 dan muka air maksimum Fr : 0.073

Berdasarkan konfigurasi dasar sungai bahwa pada bagian hilir sungai Jenelata berbentuk Anti Dunnes dengan dasar bentuk gelombang yang tidak simetris dimana nilai $\mathrm{k}>0,01$ meter

\section{UCAPAN TERIMA KASIH}

Penulis mengucapkan terima kasih kepada Rektor Universitas Muhammadiyah Makassar melalui LP3M yang telah memberi dukungan financial terhadap penelitian ini.

\section{DAFTAR PUSTAKA}

Ahmada, Rajib, 2016. Studi Ankutan Sedimen di Hilir Bendungan Karet Sungai Jeneberang. Tugas Akhir Program Sarjana Teknik Sipil Fakultas Teknik. Universitas Hasanuddin.

Alwi, dan Saenal, Andi, 2016. Pengaruh Aliran Terhadap Perubahan Pola Dasar Saluran Terbuka Dengan Material Pasir. Tugas Akhir Program Sarjana Teknik Sipil Fakultas Teknik. Universitas Muhammadiyah Makassar. 
Apriyanti, Yayuk, dan Hamabali, Roby. Studi Karakteristik Sedimen dan Laju Sedimentasi Sungai Daeng Kabupaten Bangka Barat.https://media.neliti.com. 2016.

Artia, 2018. Analisa Karakteristik Sedimen dan Laju Sedimentasi Sungai Walanae Kabupaten Wajo. Tugas Akhir Program Sarjana Teknik Sipil Fakultas Teknik. Universitas Muhammadiyah Makassar.

Cennae, A, Arbimusa, 2016. Studi Karakteristik Sedimen dan Morfologi Dasar Muara Sungai Jeneberang. Tugas Akhir Program Sarjana Teknik Sipil Fakultas Teknik. Universitas Hasanuddin.

Fahmi,Chairul, Muhammad. Pengelolaan Daerah Aliran Sungai Jenneberang Kota Makassar Sulawesi Selatan. https://staff.blog.ui.ac.id, 2014.

Haris, Muhammad, dan Tihuruah, Hajrah, 2013. Studi Pola Aliran Pada Krib Impermeabilitas Di Tikungan Sungai. Tugas Akhir Program Sarjana Teknik Sipil Fakultas Teknik. Universitas Muhammadiyah Makassar.

Haruna, Hermin, 2012. Analisa Bentuk Penampang Saluran Terhaadap Kecepatan Aliran Di Kalamisu Kabupaten Sinjai (Studi Kasus BKS 1 s.d BKS 3 ). Tugas Akhir Program Sarjana Teknik Sipil Fakultas Teknik. Universitas Muhammadiyah Makassar.

Hidayat, Rahmat dan Lahuddin, 2018. Analisa Kecepatan Aliran dan Sedimentasi Pada Saluran Primer di Kampili Kabupaten Gowa. Tugas
Akhir Program Sarjana Teknik Sipil Fakultas Teknik. Universitas Muhammadiyah Makassar.

Lubis, Murni, Astika, 2016. Analisa Sedimentasi di Sungai Way Besai. Tugas Akhir Program Sarjana Teknik Sipil Fakultas Teknik. Universitas Lampung.

Nenny, dan Al Imran, Hamzah, Pengaruh Kecepatan Aliran Terhadap Gerusan Lokal di Sekitar Pilar Heksagonal (Uji Laboratorium). http://www.unismuh.ac.id/wpontent/uploads/2018/05/F000000033 -JurnalNenny1.pdf, 2014.

Maryono, Agus, 2010, Karakteristik Resistensi Kelompok Pulau Di Sungai. Fakultas Teknik. Universitas Gadjah Mada. https://multisite.itb.ac.id

Mukhsan, dkk, Studi Penyebaran Sedimen Muara Sungai Jeneberang. https://repository.unhas.ac.id, 2013.

M.S, Pallu, dkk, Studi Eksperimen Agradasi Dasar Sungai Pada Hulu BangunanAir.

https://repository.unhas.ac.id/handel/ 123456789/9277, 2014.

Rijin, Van, Leon C, 1993, Principles of Sediment Transport in Rivers Estuaries and Coastal Seas. https://gprgiindonesi.wordpress.com

Triadmodjo, Bambang, 1993, Buku Hidraulika II. Jakarta. http://lib.ui.ac.id/opac/themes/libri2/ detail.jsp?id $=86092 \&$ lokasi $=06$ 